\title{
Why are they outstanding? Evidence from TIMSS 2007 in Hong Kong, Singapore, and Taiwan
}

\author{
JenJang Sheu \\ National Chung Hsing University/Center for Teacher Education \\ 250 Kuo-Kuang Road,Taichung,Taiwan 402
}

\begin{abstract}
This study explored the effects of individual student factors and teacher factors on eighth graders science achievement in Hong Kong, Singapore, and Taiwan. Multilevel effects were examined through Hierarchical Linear Modeling (HLM), using the Trends in International Mathematics and Science Study (TIMSS) 2007 eighth grade dataset. The results showed that selected student background characteristics, except student attitudes towards science, were significant factors leading to the outstanding science performance in these 3 countries. In general, the selected teacher variables, except teacher expectations for student achievement, were minimally related to science achievements.
\end{abstract}

\section{Introduction}

Hong Kong, Singapore, and Taiwan are 3 countries with a similar cultural heritage, ethnic background, immigrant history, colonial influence, religious background, political system, traditional family structure, and level of economic development. According to the TIMSS science report from 1999 to 2007, students in these 3 countries demonstrated excellent performance in science. Particularly at the eighth grade level, the TIMSS 2007 in Singapore and Taiwan had the highest average achievement in science; Hong Kong also performed well [25]. Hence, this research provides an overview of the performance of students from Hong Kong, Singapore, and Taiwan in the prominent international comparisons of TIMSS 2007 and addresses what kind of factors leading to the outstanding science performance in these 3 countries.

In the educational field, organizations and data structures are often hierarchical or nested, which means that individual units are grouped into larger groups; these groups of people are grouped into higher-order organizations; the organizations may be grouped at still higher levels [30]. Ignoring the influences from any level of the hierarchical structure may cause statistical and interpretational problems. To solve these problems, a multilevel analytic approach is required, which provides an integrated strategy for handling problems such as aggregation bias in standard error estimates and erroneous probability values in hypothesis testing of school effects. Two-level hierarchical linear modeling (HLM) was used to explore the relationship between eighth grade science achievement and the hypothesized factors of students and teachers among selected countries in this study. TIMSS 2007 presents information on the background characteristics of students and science teachers, to enable this study to conduct further research and discussion.

\section{Theoretical Background}

\section{Student-Level Factors and Achievement}

Attitude is a precursor to achievement (Osborne, et al., 2003). Numerous studies have shown positive attitudes toward science as an important predictor of science performance and learning [25]. To investigate how students think of their science abilities, TIMSS created an index of student selfconfidence in learning science (SCS). Studies have shown the positive relationship between selfconfidence and school achievement [21]. To investigate how students feel about science, TIMSS created an Index of Student Positive Affect toward Science (PATS). A large body of research shows that positive and negative affect influences cognitive processes that can be used as information to drive decision making and motivation [1], [2].

To possess a positive attitude toward science, students may be more attracted to science and more motivated to learn it if they perceive science achievement as advantageous to their future education and work; thus, TIMSS created an Index of Students Valuing Science (SVS). Values are defined as intrinsic reasons for people to choose and engage in a task and their extrinsic reasons for doing so. People's values influence the attractiveness of different goal objects and, consequently, the motivation to attain these goals. Expectancy value theory, regarded as one of the major frameworks for achievement motivation, highlights the pivotal role of student beliefs regarding the value of an academic task in structuring their motivation to learn [40].

Some studies showed that family socio-economic status (SES) is an important predictor of learning and achievement [28] and acts as a conduit for the influence of SES on the development of children and adolescents [31]. Numerous studies have established an empirical relationship between family SES and academic achievement [17], [19], [42] in both math and science. Empirical evidence suggests that a higher SES may lead to higher levels of achievement and promote successful children because parents 
with a higher SES are likely to invest their economic, educational, and occupational capital to facilitate the well-being of their offspring from childhood into the adult years [8].

Moreover, the role of gender on students' science achievement has long been an area of study. The data from TIMSS provide a rich source for examining gender equity both within and across countries. Gender dynamics in classrooms are often portrayed as an important environmental source of gender differences in educational outcomes [38].

\section{Teacher-Level Factors and Achievement}

This study attempted to relate teacher expectations (TCHES), teacher self-perceived preparedness (TP), years of teaching experience (TY), and teacher gender (TG) to student science achievements by using the TIMSS 2007 teacher sample among Hong Kong, Singapore, and Taiwan. Research has shown that teacher expectations of student ability, potential, success, and standards for achievement influence student learning [22], motivation [41], selfperception [33], self-concept [3], self-belief [34], student expectation, capacities [20], and classroom success [39].

As to teacher self-perceived preparedness, TIMSS 2007 asked science teachers how prepared they felt to teach a subset of the science topics included in the TIMSS 2007 science framework [25]. Teacher feelings of preparedness relate to whether they are adequately prepared to teach and are an important indicator of their profession and confidence in teaching. Teachers need to demonstrate subject matter competency and understanding in all areas that they teach, including science education. Wellprepared science teachers plan, implement, and evaluate a high quality, standards-based science curriculum. Research has indicated that teacher qualifications and preparation are important elements of teacher effectiveness, their sense of teaching efficacy, their sense of responsibility for studentlearning.

According to the literature review, the purpose of this study was to explore the effects of student- and teacher-level factors on students' science achievement at eighth grade level in Hong Kong, Singapore, and Taiwan. The TIMSS 2007 data for the 3 countries were examined using Hierarchical Linear Modeling (HLM) analysis to address the following research questions:

(1) What student-level factors are significantly related to science achievement at the eighth grade level in Hong Kong, Singapore, and Taiwan?

(2) What teacher-level factors are significantly related to science achievement at the eighth grade level in Hong Kong, Singapore, and Taiwan?
(3) How much of variance in student achievement is explained by student- and teacherlevel factors in each selected region?

(4) Is there any significant interaction effect across student-and teacher-level factors which are related to science achievement in each selected region?

\section{Method}

\section{A. Contextual model}

To understand better how student and teacher factors relate to science achievement, based on the previous literature review, the following contextual model was developed, there were two clusters of factors: student and teacher variables (Figure 1).

For student-level factors, including student gender (SG), student self-confidence in learning science (SCS), student positive affect toward science (PATS), student valuing science (SVS), and family socioeconomic status (SES) were drawn from the TIMSS 2007 student questionnaire. There are one item that refers to SG, four items that are considered related to SCS, three items investigating PATS, four items associated to SVS, and one item representing family SES. The summary for the student variables and their corresponding items are listed.

For teacher-level factors, teacher gender (TG), teacher expectations for student achievement (TCHES), teacher self-perceived preparedness (TP), and years of teaching experience (TY) were included and drawn from the TIMSS 2007 teacher questionnaire. There are one item that refers to TG, an item that represents TCHES, 27 items that detect $\mathrm{TP}$, and an item that investigates TY. The summary for the teacher variables and their corresponding items are listed.

\section{B. Participants}

Eighth grade students and their science teachers from the participating countries (Hong Kong, Singapore, and Taiwan) were the population of this study. The Hong Kong TIMSS 2007 sample consisted of 3,470 students and their 123 science teachers in 120 schools, the Singapore sample consisted of 4,599 students and their 429 science teachers in 164 schools, and the Taiwan sample consisted of 4,046 students and their 154 science teachers in 150 schools.

\section{Data Analyses}

Two-level HLM was used to explore the relationship between student science achievement and the hypothesized predictors in this analysis, where students were the level 1 and teacher were the Level 2 units. The analysis followed the three-stage approach of multilevel modeling. At the first stage, 
the analysis produced the unconditional model with no independent variables at the student- and teacherlevel. At the second stage (random coefficients model), to answer research question (1), studentlevel variables were added to the unconditional model to determine what student-level factors are significantly related to science achievement in the selected region. At the last stage (conditional model), to answer the research question (2), (3), and (4), teacher-level variables were added to the model, to examine what student-level factors are significantly related to science achievement, how much of variance in student achievement is explained by student- and teacher-level factors, and Is there any significant interaction effect across student-and teacher-level factors which are related to science achievement in each selected region? [30]. Data were analyzed by using the HLM 6.08 and SPSS 17.0.

Certain centering options can produce a mismatch between the paradigm from which the researcher is operating and the implicit paradigm operationalized analytically [18]. In random coefficients model, grand mean centering is adopted in scale variables, including SCS, PATS, SVS, and family SES. The nominal variable refers to raw metric scaling, where no centering occurs [18]; that is, student gender (SG) is used in its original metric.

In conditional model, the student-level variables, except student gender, were grand mean centered. The teacher-level variables, excluding teacher gender also in their original metrics, were grand mean centered.

The equations derived from the conditional model as the followings:

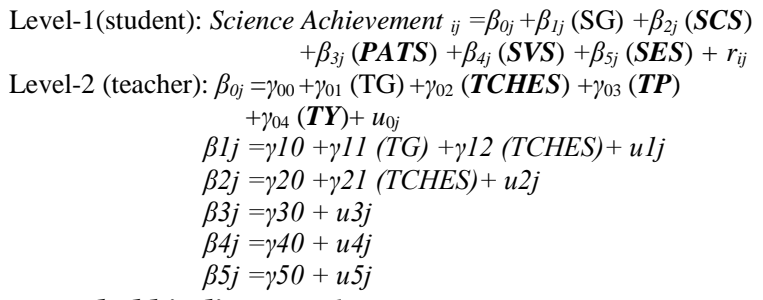

Note: bold italic: grand mean centering.

\section{Result and Discussion}

\section{Descriptive statistics of variables at the student and teacher level}

At the student-level, variables such as student selfconfidence in learning science (SCS), student positive affect toward science (PATS), student valuing science (SVS), family socioeconomic status (SES) are considered as scale variables. Likewise, at the teacher-level, teacher expectations (TCHES), teacher self-perceived preparedness (TP), and years of teaching experience (TY) are also referred to as scale variables. However, genders at both levels are nominal variable including SG ( $0=$ Girl, $1=$ Boy $)$ and TG $(0=$ Woman; $1=$ Man $)$.

Variation in science achievement: within vs. between classes

The intraclass correlation coefficient (ICC) is the proportion of variance that is between clusters, that is, the proportion of variance that can be explained by the clustering or grouping structure. The higher the ICC, the more homogeneity there is within clusters (or the more heterogeneity there is between clusters). According to unconditional model results, within-class variance in Singapore and Taiwan was larger than between-class variance. Especially in Taiwan, most of the variance was within classes (82\%), among the students in the same classroom, taught by the same teacher. Only in Hong Kong, was within-class variance smaller than between-class variance. When ICC value is higher than 0.138 , it indicates strong significant variability between groups. The ICC was 0.57 in Hong Kong, 0.48 in Singapore, and 0.18 in Taiwan; hence, the results strongly suggest that multilevel analyses were desirable in analyzing the data of each region.

\section{The effects of student-level variables}

To answer the first research question, a random coefficient model with student-level factors was run with HLM, five student factors including SG ( $0=$ Girl; 1=Boy), SCS, PATS, SVS, and family SES were added. The results showed that there was no significant difference between the science achievement of boys and girls in Singapore. Differences were significant in Hong Kong $(\mathrm{p}<0.001)$ and Taiwan $(\mathrm{p}<0.01)$. On average, boys scored approximately 11 points higher than girls in Hong Kong and 8.5 points lower in Taiwan, controlling for the SCS, PATS, SVS, and family SES factors.

Results indicated that student self-confidence in learning science (SCS), student positive affect toward science (PATS), student valuing science (SVS) and family socioeconomic status (SES), excluding SES in Hong Kong, significantly and positively affected the TIMSS 2007 eighth grade science scores in all these regions (see Table I). On average, the increases in the science scores associated with one point in SCS were 11.2 points in Hong Kong, 12.5 points in Singapore, and 15.1points in Taiwan, controlling other student-level factors. The increases in the science scores associated with one point increase in PATS were 7.3, 4.0, and 12.5 points, respectively, controlling for other studentlevel factors. As to SVS, the increases in the science scores associated with one point increase in SVS were 4.7 points in Hong Kong, 11.7 in Singapore, and 9.8 points in Taiwan, controlling for other student-level factors. Regarding family socioeconomic status, then the increases in the 
science scores associated with one point in SES were 13.0 points in Singapore and $\mathbf{1 7 . 5}$ points in Taiwan, controlling other student-level factors.

\section{The effects of teacher-level factors}

To answer the second, third and fourth research questions, a conditional model with all five studentlevel variables (i.e., SG, SCS, PATS, SVS, and family SES ) and four teacher-level variables (i.e., TG, TCHES, TP, and TY ) was run with HLM. The second research question: What teacher-level factors are significantly related to science achievement at the eighth grade level in Hong Kong, Singapore, and Taiwan? In general, there are no significant relations between the teacher's gender (TG), years of teaching experience (TY), and teacher self-perceived preparedness (TP) and the TIMSS 2007 science scores in all these 3 regions, excluding the teacher self-perceived preparedness (TP) in Hong Kong $(p<0.01)$ was a negative relation with student science scores, and it's quite unusual(see Table I). Teacher expectation (TCHES) was significantly related to science scores all in Hong Kong $(\mathrm{p}<0.01)$, Singapore $(p<0.001)$ and Taiwan $(p<0.05)$. Teachers owned more expectation to their students leading to achieve higher scores on the science test compared to their counterparts in other classes. In Hong Kong students scored 13.2 points $(18.38 \times 0.72), 18.8$ points (25.44x0.74) in Singapore, and in Taiwan, 5.5 points (6.99x0.79) higher with one standard deviation increase with the teacher expectation, when all the other factors were held constant.

\section{Explained variances in science achievement}

The third research question: How much of variance in student achievement is explained by student- and teacher-level factors in each selected region? Applying Snijders and Bosker formula [37] to evaluate the student level proportional reduction in prediction error in is in Hong Kong 5\%, in Singapore $21 \%$, and in Taiwan 29\%. The teacher level proportional reduction in prediction error is $11 \%$ in Hong Kong, 35\% in Singapore, and $41 \%$ in Taiwan. It should be noted that $43 \%$ of the variance in science scores was within classes in Hong Kong, $52 \%$ in Singapore and $82 \%$ in Taiwan (see Figure 2). In other words, student-level factors explained only about $2 \%(5 \% \times 43 \%)$ of total variance in Hong Kong, $11 \%$ in Singapore, and 24\% (29\%x82\%) in Taiwan. As to teacher-level factors, which explained about $5 \%(11 \% \times 47 \%)$ of total variance in Hong Kong, $17 \%$ (35\%x48\%)in Singapore, and 7\% (41\%x18\%) in Taiwan.

\section{Interaction effects in contextual system}

Regarding research question 4: Is there any significant interaction effect across the teacher-level and student-level and how are they associated with science achievement in each selected region? To answer it, the conditional model was conducted for each region. In Singapore, there indicated an interaction effect between the student self-confidence in learning science (SCS) and science achievement and was moderated by teacher expectations for student achievement (TCHES). Thus, the regression of science achievement on SCS varied across the value range of the degree of TCHES. The equation that involves the coefficient of the two predictor variables and their interaction can be extracted from below equation.

Science Achievement ${ }_{\mathrm{ij}}=559.64+30.52 *$ TCHES $_{\mathrm{j}}+$ $(21.22+4.51 * \boldsymbol{T C H E S}) * \boldsymbol{S C} \boldsymbol{S}_{\mathrm{ij}}+\mathrm{u}_{0 \mathrm{j}}+\mathrm{u}_{1 \mathrm{j}} * \boldsymbol{S C} \boldsymbol{S}_{\mathrm{ij}}+r_{\mathrm{ij}}$

Note. Bold italic: grand-mean centering.

The value of teacher expectations for student achievement (TCHES) is set at - low TCHES: -1, middle TCHES: 0 , and high THCES: 1 , which are the values of one standard deviation below the mean, the mean, and one standard deviation above the mean. Figure 4 shows the plot of the three regression lines.

Among different levels of TCHES, high TCHES have the strongest effect on science achievement than the others. In multilevel analysis, where the interest often lies in contextual effects, the interpretation that the effect of SCS is moderated by TCHES would in many cases be preferred. Students who are more confident in science have higher science achievement, and that difference is larger with higher teacher expectation.

\section{Conclusion}

Numerous researchers are interested in the interrelationship between student science achievement and their other related attitudinal and affective variables, which seem to emerge as salient factors affecting science achievement. Ample evidence from previous studies has also shown that student achievement is related to student attitudes, including student general attitudes toward science (PATS), the value they place on science as a way of improving their lives (SVS), and their selfconfidence in learning science (SCS). Among the student factors, researchers have found family SES as one of the particularly important home background factors deeply influencing the development and achievement of children and adolescents [24], [31]. Therefore, exploring the influences of adolescent affective characteristics and their family SES on science achievement is meaningful.

Teacher characteristics and student achievement growth are currently a significant topic of investigation in the educational accountability arena. Accordingly, a new era of research is needed to 
understand how the complexity of teacher characteristics influences student learning and performance. TIMSS presents information on the background characteristics of science teachers, including gender (TG), years of teaching experience (TY), and how well prepared teachers feel to teach science (TP), which allows this study to conduct further research and discussion. This research attempts to discover the influences of teacher expectations on science achievement and explores its interaction effects among all other student-level factors. Finally, the gender issue remains a very popular issue and plays an important role in the educational field. However, numerous studies have incorporated the gender issue into their analyses, resulting in mixed results in the literature. Thus, this research also focuses on the gender issue in science learning by adding the factors of student gender and teacher gender to discover the interaction between them and their effects on student science performance.

This cross-national comparison study of the TIMSS 2007 used two-level HLM to explore the relationship between eighth grader science achievement and the hypothesized predictors of teachers and students in Hong Kong, Singapore, and Taiwan. Form the ICC analysis of the variance of between groups is Hong Kong (57\%), Singapore (48\%), and Taiwan (18\%); hence, it strongly suggested that multilevel analyses are desirable in analyzing the data in this study.

\section{Findings of student-level factors}

Among the student-level predictors, student selfconfidence in learning science (SCS) and student valuing science (SVS) were obviously important variables because they had a positive significant relationship with student science achievement after controlling for other variables in all these 3 selected countries. Previous research has also shown the positive relationship between self-confidence and school achievement [21]. Besides, student positive affect toward science (PATS) had a significant effect on science achievement in Hong Kong and Taiwan; a higher positive affect toward science in students may lead them to higher science achievement. Studies have also shown that when the link between performance and outcomes is made explicit, positive affect improves people's performance and affects their perceptions of expectancy and valence, hence leading to enhanced achievement, higher motivation, and greater persistence [1].

Family SES played an important role in science achievement both in Singapore and Taiwan, and the result refers to the significant positive connection between family SES and science achievement, meaning that a higher family SES led to higher science performance. Empirical evidence also suggests that a higher SES may lead to higher levels of achievement [28] and promote successful children [8].

The gender dynamic in classrooms is frequently portrayed as an important environmental source of gender differences in educational outcomes [38]. Both in Hong Kong and in Taiwan, student gender (SG) had a significant effect on science achievement, although the result showed that in Hong Kong, boys performed better than girls in science, whereas in Taiwan, girls performed better on science tests than did boys. However, student gender had no significant effect on science achievement in Singapore. Certain studies have indicated that gender differences in average test scores identify only some of the manners in which the educational outcomes of boys and girls differ [11].

\section{Findings of teacher-level factors}

The results indicate that the pattern for the significant teacher-level variable was nearly the same for Hong Kong, Singapore, and Taiwan. Among the three regions, teacher expectations for student achievement (TCHES) were an important predictor, and had a strong, positive, and significant effect on student science achievement. Students in whom teachers held high expectations were given more leadership and learning opportunities, and perceived more positive academic feedback from teachers, which correlated with high self-concept ratings [3], whereas for low expectation, the association of teacher expectation and all student factors is significant and negative [34].

This study results also showed that certain variables from the teacher level had no significant effect or even a negative effect on student science achievement. For instance, teacher gender (TG) and years of teaching experience (TY) had no significant effect on student science achievement in these 3 regions. Teacher self-perceived preparedness (TP) had a significant negative association with student science achievement in Hong Kong (a little strange!), but had no significant effect on student science performance in Taiwan and Singapore. Regarding years of teaching experience (TY), previous research has shown the same result as this study did. Some have shown that the effect of teacher experience is weakly related to student learning [4], whereas other studies have found teacher experience to be unimportant, and noted no significant results for student achievement [9]. Researchers have indicated that although teaching experience at a particular grade level showed a statistically significant association with academic achievement gains, rewarding years of teaching at grade level, not just years of teaching alone, are more important to consider in an effort to improve student achievement. Previous research has indicated teacher gender to have a changing effect on student performance [4], 
and gender interactions between teachers and students have a statistically significant effect on a diverse set of educational outcomes [11]. However, the evidence of this study shows that teacher gender is not a significant predictor of science achievement, and no interaction effect exists between teacher gender and student gender in Hong Kong, Singapore, and Taiwan. Further research may be needed in gender issues.

Findings on the interaction effect across levels

Among these 3 selected countris, there is only a significant cross level interaction effect exists in Singapore. The interaction effect between teacher expectations for student achievement (TCHES) and student self-confidence in learning science (SCS) was positively related to student science achievement, indicating that the stronger the interaction effect between teacher expectations and SCS, the higher the student science scores were. According to the evidence in Singapore (rank $1^{\text {st }}$ in TIMSS 2007), teacher expectation is a powerful factor, which can lead to an interaction effect on student self-confidence and science achievement. Therefore, the issue of teacher expectation worth be re-addressed in the future.

Based on results of this study, student selfconfidence in learning science (SCS), student positive affect toward science (PATS), student valuing science (SVS), family SES, and teacher expectations for student achievement (TCHES) were important factors leading to the outstanding science performance in these 3 regions. The results also showed the similar pattern for Hong Kong, Singapore, and Taiwan eighth graders about why they are outstanding in TIMSS 2007.

\section{References}

[1] Armitage, C. J. (2008). Cognitive and affective predictors of academic achievement in schoolchildren. British Journal of Psychology, 99(1), 57-74.

[2] Armitage, C. J., Conner, M., \& Norman, P. (1999). Differential effects of mood on Information processing: Evidence from the theories of reasoned action and planned behaviour. European Journal of Social Psychology, 29, 419-433.

[3] Bae, S., Holloway, S. D., Li, J., \& Bempechat, J. (2007). Mexican-American Students' Perceptions of Teachers' Expectations: Do Perceptions Differ Depending on Student Achievement Levels? The Urban Review, 40(2), 210-225.

[4] Buddin, R., \& Zamarro, G. (2009). Teacher qualifications and student achievement in urban elementary schools. Journal of Urban Economics, 66(2), 103-115.
[5] Chepete, P. (2010). Molding TIMSS Data: Botswana Data as an Example: Analysis of multilevel data: TIMSS Saarbrucken, Germany LAP Lambert Academic Publishing.

[6] Clogg, C. C., \& Shihadeh, E. S. (2002). Statistical models for ordinal variables. In A. Bryk, S, \& S. Raudenbush, W, (Eds.), Hierarchical Linear Models Appications and Data Analysis Methods (2nd ed.). Thousand Oaks, CA: Sage.

[7] Clotfelter, C. T., Ladd, H. F., \& Vigdor, J. L. (2006). Teacher-Student Matching and the Assessment of Teacher Effectiveness. Journal of Human Resources, XLI(4), 778820.

[8] Conger, R. D., \& Donnellan, M. B. (2007). An Interactionist Perspective on the Socioeconomic Context of Human Development. Annual Review of Psychology, 58(1), 175-199.

[9] Croninger, R., Rice, J., Rathbun, A., \& Masako, N. (2007). Teacher qualifications and early learning: Effects of certification, degree, and experience on first-grade student achievement. Economics of Education Review, 26, 312-324.

[10] Preparation: How Well Do Different Pathways Prepare Teachers to Teach? Journal of Teacher Education, 53(4).

[11] Dee, T. S. (2005). Teachers and the Gender Gap in Student Achievement. Cambridge, MA: National Bureau of Economic Research.

[12] Duffy, J., Warren, K., \& Walsh, M. (2001). Classroom Interactions: Gender of Teacher, Gender of Student, and Classroom Subject. Sex Roles: A Journal of Research, 45(9), 579-593.

[13] Foy, P., Galia, J., \& Li, I. (2008). Scaling the Data from the TIMSS 2007 Mathematics and Science Assessments. Chapter 11. In J.F. Olson, M. O. Martin \& I. V. S. Mullis (Eds.), TIMSS 2007 technical report (pp. 225279). Chestnut Hill, MA: TIMSS \& PIRLS International Study Center, Boston College.

[14] Foy, P., \& Olson, J. F. (2009). TIMSS2007 UserGuide for the International Database: Chestnut Hill: MA: TIMSS \& PIRLS International Study Center, Boston College

[15] Goldhaber, D. (2008). Teachers matter, but effective teacher quality policies are elusive. In H. F. Ladd \& E. B. Fiske (Eds.), Handbook of research in education finance and policy (pp. 146-165): Routledge.

[16] Hill, H. C., Rowan, B., \& Ball, D. L. (2005). Effects of Teachers' Mathematical Knowledge for Teaching on Student Achievement. American Educational Research Journal, 42(2), 371-406.

[17] Hochschild, J. L. (2003). Social Class in Public Schools. Journal of Social Issues, 59(4), 821-840. 
[18] Hofmann, D. A., \& Gavin, M. B. (1998). Centering Decisions In Hierarchical Linear Models: Implications for Research in Organizations. Journal of Management, 24(5), 623-641.

[19] Jeynes, W. H. (2002). Examining the effects of parental absence on the academic achievement of adolescents: the challenge of controlling for family income. Journal of Family and Economic Issues, 23(2), 189-210.

[20] Justo, C. F. (2008). Effects of teacher expectations on the development of verbal creativity in childhood education. Actualidades Investigativas en Educación, 8(3), $1-14$.

[21] Kleitman, S., \& Moscrop, T. (2010). Self-confidence and academic achievements in primary-school children: Their relationships and links to parental bonds, intelligence, age, and gender. In A. Efklides \& P. Misailidi (Eds.), Trends and prospects in metacognition research (pp. 293-326). NewYork, NY: Springer.

[22] Koh, C., Wang, C. K. J., Tan, O. S., Liu, W. C., \& Ee, J. (2009). Bridging the Gaps between Students' Perceptions of Group Project Work and Their Teachers' Expectations. Journal of Educational Research, 102(5), 333-348.

[23] Kreft, I. G. G., \& Leeuw, D. J. (1998). Introducing multilevel models. London: Sage.

[24] Marjoribanks, K. (1996). Family Learning Environments and Students' Outcomes: A Review. Journal of Comparative Family Studies, 27(2), 373-339.

[25] Martin, M. O., Mullis, I. V. S., Beaton, A. E., Gonzalez, E. J., Smith, T. A., \& Gregory, K. D., et al. (2000). TIMSS 1999 International Science Report: Findings from IEA's repeat of the Third International Science and Science Study (TIMSS) at the eighth grade. Chestnut Hill, MA: Center for the Study of Testing, Evaluation, and Educational Policy, Boston College.

[26] Myers, T. A. (2011). Goodbye, Listwise Deletion: Presenting Hot Deck Imputation as an Easy and Effective Tool for Handling Missing Data. Communication Methods and Measures, 5(4), 297-310.

[27] Neathery, M. F. (1997). Elementary and secondary students' perceptions toward science: Correlations with gender, ethnicity, ability, grade and achievement. Electronic Journal of Science Education, 2(1). Retrieved from http://ejse.southwestern.edu/article/view/7573/5340

[28] O'Dwyer, L. M. (2005). Examining the variability of mathematics performance and its correlate using data from TIMSS' 95 and TIMSS' 99 Educational Research and Evaluation, 11(2), 155-177.

[29] Osborne, J., Simon, S., \& Collins, S. (2003). Attitude towards science: A review of the literature and its implications. International Journal of Science Education, 25(9), 1049-1079.
[30] Raudenbush, S. W., \& Bryk, A. S. (2002). Hierarchical Linear Models: Applications and Data Analysis Methods (2nd ed.). Thousand Oaks, CA: Sage.

[31] Repetti, R. L., Taylor, S. E., \& Seeman, T. E. (2002). Risky families: family social environments and the mental and physical health of offspring. Psychol Bull, 128(2), 330-366.

[32] Rivkin, S. G., Hanushek, E. A., \& Kain, J. F. (2005). Teachers, Schools, and Academic Achievement. Econometrica, 73(2), 417-458.

[33] Rubie-Davies, C. M. (2006). Teacher expectations and student self-perceptions: Exploring relationships. Psychology in the Schools, 43(5), 537-552.

[34] Rubie-Davies, C. M., Peterson, E., Irving, E., Widdowson, D., \& Dixon, R. (2010). Expectations of Achievement: Student, Teacher and Parent Perceptions. Research in Education, 83(1), 36-53.

[35] Sadker, D. (2002). An Educators' Primer to the Gender War. Phi Delta Kappan, 84(3), 235-244.

[36] Smith, D. (1991). Classroom interaction and gender disparity in secondary vocational instruction. The Journal of Vocational Education Research, 16, 35-58.

[37] Snijders, T. A., \& Bosker, R. J. (1999). Multilevel Analysis: An Introduction to Basic and Advanced Multilevel Modeling. Thousand Oask: Sage Publications.

[38] Sommers, C. H. (2000). The War Against Boys: How Misguided Feminism is Harming Our Young Men. New York: Simon and Schuster.

[39] Trouilloud, D. O., Sarrazan, P. G., Martinek, T. J., \& Guillet, E. (2002). The influence of teacher expectations on student achievement in physical education classes: Pygmalion revisited. European Journal of Social Psychology 32(5), 591-607.

[40] Velayutham, S., Aldridge, J., \& Fraser, B. (2012). Gender differencesin student motivation and selfregulation in science learning: a multi-group structural equation modeling analysis. International Journal of Science and Mathematics Education, 1-22.

[41] Wigfield, A., \& Eccles, J. S. (2000). ExpectancyValue Theory of Achievement Motivation. Contemporary Educational Psychology, 25(1), 68-81.

[42] Yang, Y. (2003). Dimensions of socio-economic status and their relationship to mathematics and science achievement at individual and collective levels. Scandinavian Journal of Educational Research, 47(1), 2141. 